\title{
EDUCAÇÃO NA VELHICE? UMA HISTÓRIA DE 11 ANOS NA UNIVERSIDADE FEDERAL DO TOCANTINS
}

Old Education? A History of 11 Years at the Federal University of Tocantins

Educación en Velhice? Una Historia de 11 años en la Universidad Federal del Tocantins

\section{Luiz Sinésio Silva Neto* ${ }^{1}$, Neila Barbosa Osório ${ }^{1}$.}

${ }^{1}$ Universidade da Maturidade, Docente do Curso de Medicina, Universidade Federal do Tocantins, Palmas, Brasil.

*Correspondência: Universidade da Maturidade, Av. NS 15, 109 Norte, Palmas, Tocantins, Brasil. CEP:77.010-

090.e-mail: luizneto@uft.edu.br

Publicado em 15/09/2017.

Educação na velhice? Sim, esse questionamento permeia a proposta do projeto Universidade da Maturidade da Universidade Federal do Tocantins (UMA/UFT) desde sua idealização. Ao analisar a literatura, nota se que a temática velhice é pautada na pobreza, violência ou saúde. Porém, as repercussões do processo de envelhecimento populacional devem ser avaliadas de forma mais ampla e integrada. A educação na maturidade encontra se em plano secundário nas agendas públicas e científicas. Nesse sentido, a Universidade da Maturidade (UMA/UFT) contemporiza o debate a propósito dessa temática para os maduros. $\mathrm{O}$ editorial confere problematizações sobre a educação na velhice com a práxis no projeto UMA/UFT.

Como a comunicação é breve, propomos destacar três questões adjuvantes que são elas, princípios metodológicos ou a "gerontogogia", corpo docente qualificado e ambiente educacional.

A gerontogogia enquanto ciência pretende esclarecer e dar suporte às necessidades, potencialidades e ações que derivam da longevidade com possíveis implicações educacionais envolvidas (Both 2001). Essa proposta específica para os maduros é reforçada por Escarbajal (2009) que ressalta ser um lamentável erro considerar a educação de velhos nas mesmas perspectivas utilizadas em outras etapas da vida. Por isso, a gerontogogia tem como finalidade promover uma educação capaz de abranger aspectos afetivos, cognitivo e ao bem-estar social dos velhos, amplia de tal modo o significado do envelhecimento e a identidade humana. A UMA/UFT possui um currículo desenvolvido que estimula a reflexão do sujeito sobre a expectativa do seu envelhecimento e dessa maneira determina a sua motivação para as ações educacionais. Isso explica a vontade dos velhos em não perder o vínculo com o projeto, frases como "Eu não saio mais daqui até o fim dos meus dias" são comuns nas falas dos acadêmicos.

Outro fator importante a ser debatido na educação na velhice é a prática docente. De acordo com Cachioni (2015) no Brasil, raras são as referências ao educador. Não possuímos uma área definida para a sua formação. Questões ainda encontram sem respostas tais como: que tipo de formação está sendo oferecida? Em que suportes teóricos e metodológicos se apoiam essa formação? Destacamos, a necessidade de intercâmbio cientifico com outros países que possuem vasta experiência, tais como, França, Bélgica, Suíça, Portugal e Holanda. Na experiência da UMA/UFT salientamos, 
o grupo de pesquisa Pro-Gero Envelhecimento Humano, que possui pesquisadores a atuar na linha de pesquisa de formação de professores e processos de aprendizagem na velhice. No Programa de PósGraduação Mestrado em Educação é desenvolvida a disciplina "Tópicos especiais em educação intergeracional", especialmente nesse ano um aluno do programa realiza um intercâmbio em Portugal. Além, da Pós-Graduação Latu Sensu em Gerontologia iniciada desde 2005.

$\mathrm{O}$ termo ambiente educacional utilizado nesse editorial refere se ao conjunto de elementos, de ordem material ou afetiva, que circunda o educando, que nele deve necessariamente se inserir e que o inclui, quando vivencia os processos de ensino e aprendizado, e que exerce influência definida sobre a qualidade do ensino e a eficácia do aprendizado. Nesse sentido, Both (2001) destaca que esse espaço é uma forma de promover uma educação para o envelhecimento por meio do oferecimento $\mathrm{e}$ efetivação institucional para atender as reivindicações da população velha. O projeto UMA/UFT possui sede própria com uma infraestrutura composta por auditório, salas de formação, secretarias, laboratório de novas tecnologias, copa entre outros ambientes educacionais e administrativos, exclusivamente para o desenvolvimento do projeto. Esse ambiente educacional além da estrutura material de qualidade também possui o componente afetivo, para os velhos a sede é considerada sua "segunda casa". Segundo Osório (2009) o espaço se tornou um ambiente intergeracional, pois acadêmicos dos diversos cursos de graduação, liga acadêmica de geriatria e gerontologia e pós-graduação realizam projetos de extensão e pesquisa. Para vários a sede é "UMA casa de Avós".

Portanto, notadamente que o debate sobre o tema é de grande extensão. Ao mesmo tempo em que ser velho é novo na educação, o envelhecimento populacional e as mudanças rápidas do mundo contemporâneo tornam o avanço deste campo de estudo cada vez mais necessário. Nossas experiências no trabalho educativo com os velhos há 11 anos na UMA/UFT, atestam a eficiência de como a educação pode produzir novas imagens e novos saberes em relação aos velhos. Educação na Velhice? Sim. O futuro dos velhos é hoje. Eles não podem mais esperar.

Todos os autores declararam não haver qualquer potencial conflito de interesses referente a este artigo.

\section{REFERÊNCIAS}

BOTH, A. Educação Gerontológica: posições e proposições. Erechim: Ed. São Cristóvão, 2001.

CACHIONI, M. Metodologias e estratégias pedagógicas utilizadas por educadores de uma Universidade Aberta à Terceira Idade. Educação \& Realidade, v. 40, n. 1, 2015.

ESCARBAJAL, A.H. Personas Mayores, Educación y Emancipación. In: ÓPEZ, M.M, ESCARBAJAL, A.H. Alternativas Socioeducativas para las Personas Mayores. Madrid: Dykinson, 2009. OSÓRIO, N.B; Silva Neto LS. Interdisciplinaridade na terceira idade: o caso dos avós. São Paulo: Xamã, 2009. 